foreign seeds in commercial American linseed is unfounded.

In preparing the oil, the seed was ground in a coffeemill, placed in a Mason jar and steam introduced, the jar covered and placed in a steam oven for 2 hours. On removal, the meal was at once packed in cloth and placed in the press, the piston inserted and, using the screw of a filter-press, pressure was applied, the oil draining through the outlet tube into a bottle wired to the press. The first test-run showed that only slightly more oil was left in the cake than in regular factory practice.

Table II contains the analytical results obtained on the oils. In all cases, the oil was filtered through paper before making a determination. Sample $2 \mathrm{~A}$ is an extraction process oil; all the other factory samples are oils manufactured by the old process hydraulic method.

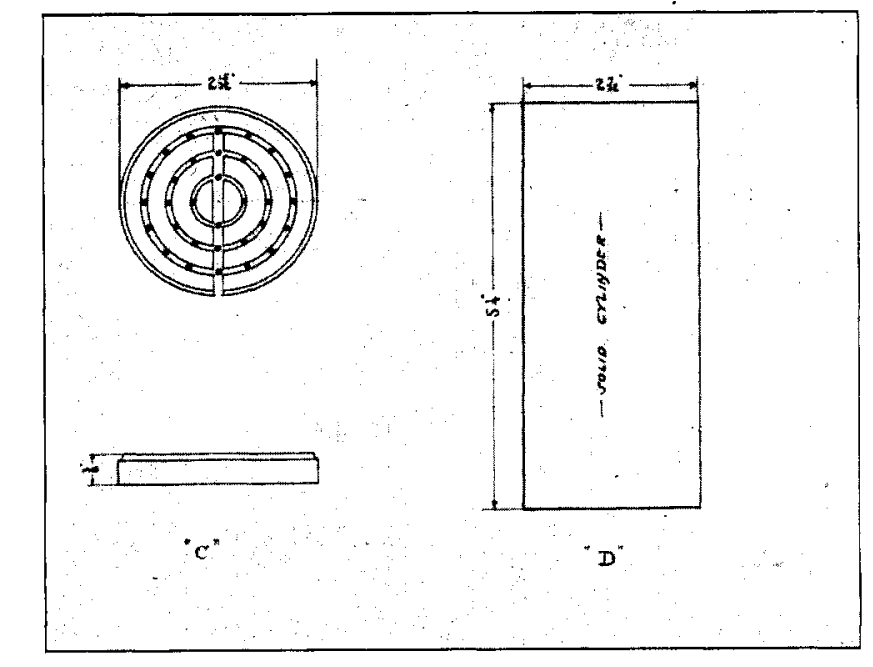

- Fig. 3.

Analyses: IA and $2 \mathrm{~A}$ give the results obtained recently on the factory samples of oil, while $\mathrm{IA}_{1}$ and $2 A_{1}$ are the results obtained two years ago on the same samples, indicating that no change in the constants determined took place in the oils. Samples I $B,{ }_{I} C$ and ${ }_{2} C$ were pressed in the laboratory from seed kept $2^{\mathrm{I}} / 2$ years in closed Mason jars.

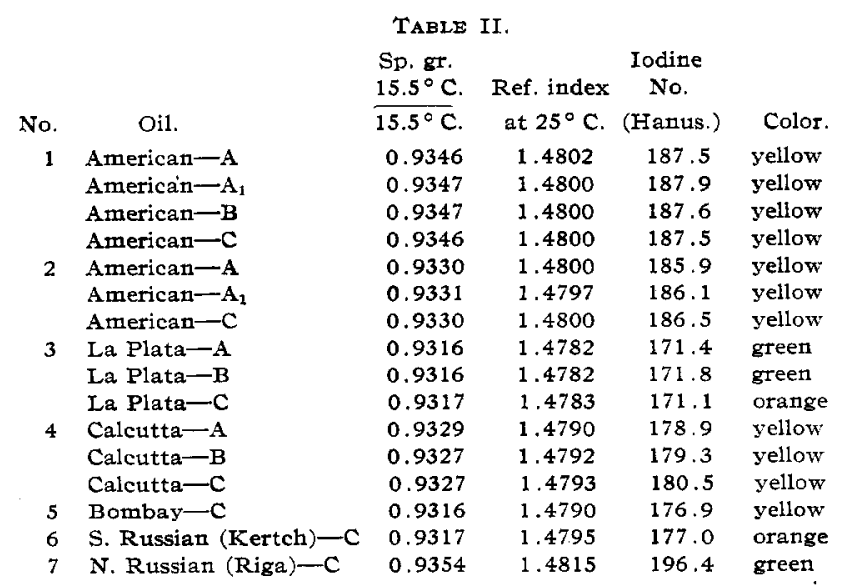

So far as the writer knows, no figures have been published giving the analysis of oils from picked seed, with the exception of Thomson and Dunlop ${ }^{x}$ who obtained 205.4 as the iodine no. on oil from picked Riga seed, but they used the Wijs method. Ketel and Antusch ${ }^{2}$ give data of the effect on the oil of varying amounts of dotter and rape seeds added to clean linseed, but they used the extraction method for obtaining the oil; while, in a later articles they admit the possibility of a lower iodine no. in extracted oil, they state that to their knowledge this has never been actually tested. It may also be mentioned that the amounts of dotter and rape seeds added are considerably out of proportion to those actually present in the commercial seed examined.

Mastbaum states" that "expressed oil has a higher iodine no. than extracted oil." The comparative analysis of $2 \mathrm{~A}$ and ${ }_{2} \mathrm{C}$ would seem to indicate, however, that this is not necessarily so.

It is worthy of note that high percentages of nonoleaginous and low percentages of oleaginous impurities, as in the La Plata seed, do not affect the constants, but do affect the color of the oil. On the other hand, with the Calcutta seed, the variation in iodine no. can hardly be due to experimental error-more likely to the high per cent. of oleaginous impuritieswhereas the color is only slightly affected. The green color of the Riga oil must be due to some coloring matter present in the seed itself.

The typical analyses quoted in Table II fall well within the limits set by Wijs when the usual difference between the Hanus iodine no. and the Wijs no. is considered.

From a consideration of the results it appears that

I. Oil pressed from clean linseed does not differ materially from commercially pure linseed oil.

2. The dark green color of the La Plata oil is due to the non-oleaginous impurities.

3. A high per cent. of oleaginous impurities does not affect the color appreciably, but does affect the iodine no. slightly.

4. The technical manufacture of oil by the extraction process does not lower the iodine no.

5. The constants of the oil pressed from the seed which had been kept $2 \mathrm{r} / 2$ years in a closed container do not appear to be affected by the aging of the seed.

IABORATORY NATIONAL LEAD COMPANY, BROOKLYN, N. Y

\section{ARSENIC IN GLASS.}

By S. R. Scholes.

Received November 13, 1911.

In Hovestadt's excellent work on "Jena Glass" arsenic oxide $\left(\mathrm{As}_{2} \mathrm{O}_{5}\right)$ is listed among the constituents of many of the glasses described, in quantities of from 0.2 to 0.4 per cent. The English edition of this book contains a note by Everett, the senior translator.

1 Analyst, 1906, 282.

${ }^{2}$ Loc. cit.

${ }^{3} Z$. angew Chem., 1897, 210

${ }^{4}$ Ibid., 1896, 719. 
who takes exception to this view, arguing that the pentoxide would be reduced at the glass-making temperature. Rosenhain, author of "Glass Manufacture," supports the latter opinion, and adds that he believes very little arsenic remains in the glass at all. It seemed of interest, therefore, to study this question from the analytical standpoint, by examination of the glass itself. Some unexpected results were obtained.

Two varieties of glass were analyzed for arsenic: No. I, a soda-baryta glass, of fairly high alkali-content; No. 2, a potash-lead glass, used for cut-glass ware. In No. I, the arsenious oxide put into the batch, or raw materials, was between 0.3 and 0.5 per cent. of the glass produced, while in No. 2 it was approximately 0.45 per cent. In both these batches, potassium nitrate was used in considerable quantity, and in No. 2 red lead was one of the main constituents, so that there was abundant opportunity for the initial oxidation of the arsenic to the pentavalent condition. The method used for determining the percentage and state of oxidation of the arsenic remaining in the glass was as follows:

Samples of glass, powdered to pass a 40-mesh sieve, were weighed into a platinum dish and treated with I $5-20 \mathrm{cc}$. of hydrofluoric acid, added in three portions. When reaction had ceased, $20 \mathrm{cc}$. of 30 per cent. sulphuric acid were added, and the mixture evaporated on a water-bath until hydrofluoric acid fumes ceased coming off. It was then rinsed into a beaker, making a total volume of $40 \mathrm{cc}$, and arsenic acid determined by titration after the manner described in Sutton's "Volumetric Analysis." In the case of the lead glass, the solution was filtered before the addition of potassium iodide, to remove the lead sulphate and avoid formation of lead iodide. After titrating with thiosulphate, the solution was nearly neutralized with sodium carbonate, $20 \mathrm{cc}$. of a saturated solution of sodium bicarbonate were added, the arsenious acid was titrated with iodine, and the arsenious oxide originally present determined by difference. The standard solutions used were twentieth-normal. Blank determinations showed that the reagents contained no measurable quantity of arsenic. The data obtained are tabulated below.

\begin{tabular}{cccccccc}
\multicolumn{9}{c}{ Cc. $N / 20$} & & & Per & Per \\
Glass. Grams & $\begin{array}{c}\text { Gio- } \\
\text { thio. } N / 20\end{array}$ & & & $\begin{array}{c}\text { cent. } \\
\text { cent. }\end{array}$ \\
No. & sample. & sulphate. & iodine. & $\mathrm{As}_{2} \mathrm{O}_{5}$. & $\mathrm{As}_{2} \mathrm{O}_{3}$. & $\mathrm{As}_{2} \mathrm{O}_{5}$. & $\mathrm{As}_{2} \mathrm{O}_{3}$. \\
1 & 6.60 & 9.0 & 9.1 & 0.02587 & 0.0003 & 0.39 & 0.00 \\
1 & 4.82 & 4.2 & 5.1 & 0.01207 & 0.0022 & 0.25 & 0.05 \\
2 & 4.25 & 5.9 & 6.6 & 0.01696 & 0.0017 & 0.40 & 0.04 \\
2 & 7.73 & 9.6 & 9.6 & 0.02760 & 0.0000 & 0.36 & 0.00 \\
$2^{1}$ & 6.00 & 8.6 & 8.6 & 0.02472 & 0.0000 & 0.41 & 0.00
\end{tabular}

These results indicate that a great part of the arsenic used in glass-making remains in the glass as the higher oxide, probably as arsenate of soda or potash. This is somewhat surprising, in view of the properties attributed to arsenic in justification of its use. It is expected to volatilize, aiding in the mixing of the batch as the latter melts. Moreover, it is said to have an oxidizing effect, but the fact that the arsenious

\footnotetext{
1 Sample fused with sodium carbonate and dissolved in sulphuric acid.
}

oxide originally employed appears finally in the glass with a gain of oxygen does not bear out this belief. On the contrary, it seems that the use of arsenic must reduce the available oxygen of the batch. At least in cases where nitrates are present and the melting carried on in closed pots, as in the manufacture of the glasses here examined, the value of the arsenic, if any, obviously lies in neither its volatilizing nor its oxidizing powers.

The glass used and the data concerning it were furnished by one of the glass companies of this vicinity.

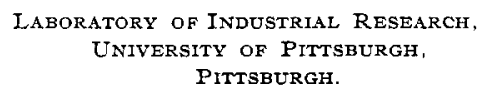

\section{THE DETERMINATION OF CHROMIUM AND ITS SEPARA- TION FROM VANADIUM IN STEELS.}

By J. R. CAIN.

Received November 10, 1911.

While attempting, recently, to determine chromium in chrome-vanadium steels, difficulties with some of the usual methods were encountered. If a steel containing chromium as chromate and vanadium as vanadate is titrated against ferrous solutions, using ferricyanide to indicate the point at which all the vanadium and chromium are reduced and an excess of titrating solution is present, there is sometimes an indefinite end-point, because as soon as some vanadium is reduced to the vanadyl condition this reacts with the ferricyanide indicator, reducing it to ferrocyanide which then gives the usual color with the ferric salts present. ${ }^{1}$ An experienced operator can oftentimes judge the end-point sufficiently closely for practical work, but the difficulty increases with increasing vanadium, and it is almost always necessary to run blanks of various kinds, increasing to that extent the uncertainties of such methods. If the excess of ferrous solution is titrated back with permanganate some correction is also necessary for chromium oxidized by permanganate. ${ }^{2}$ If in the preliminary oxidation of the vanadium and chromium, any manganese dioxide separates, as where potassium permanganate or potassium chlorate are used, some chromium may be, and often is, carried down by the manganese. ${ }^{3}$ If, in order to separate vanadate from chromate, the nitric acid solution of the steel (with or without preliminary ether extraction of most of the iron) is poured into excess of sodium hydroxide solution and boiled, usually an appreciable amount of chromium goes into the filtrate with the vanadium. Many methods take no account of this chromium. The amount so lost increases with the manganese in the steel and the time of boiling, the manganese being converted in part to peroxide and this, in the strongly alkaline solution, oxidizing the chromium to chromate. 4

Many careful tests having shown that chromium in

1 Cain, This Journal, 3, 476 (1911); other references will be found here. 2 Cain, loc. cit.

"Arnold and Ibbottson, "Steel Works Analysis," 3rd Ed., p. 180': also Cain, loc, cit.

${ }^{4}$ Cain, loc. cit. 